\title{
Assessment of Safety and Health Performance Based on ELMERI Index in One of the Steel Industries in Khuzestan Province, Iran
}

\author{
Rouhollah Kazemi', Leila Nematpour², Seyed Amin Jazayeri ${ }^{3, *}$ \\ ${ }^{I}$ Assistant Professor, Department of Environmental Management, Ahvaz Branch, Islamic Azad University, Ahwaz, Iran \\ 2 Department of Occupational Safety and Health Engineering, Faculty of Health, Ahvaz Jundishapur University of Medical \\ Sciences, Ahvaz, Iran \\ ${ }^{3} \mathrm{MSc}$, Department of Environmental Management, Ahvaz Branch, Islamic Azad University, Ahwaz, Iran \\ * Corresponding Author: Seyed Amin Jazayeri, Department of Environmental Management, Ahvaz Branch, Islamic Azad \\ University, Ahwaz, Iran.Email: Aminj.hse57@gmail.com
}

Received: 09/09/2018

Accepted: 12/02/2019

How to Cite this Article: Kazemi $R$, Nematpour $L$, Jazayeri SA. Assessment of Safety and Health Performance Based on ELMERI Index in One of the Steel Industries in Khuzestan Province, Iran. J Occup Hyg Eng. 2019; 5(4): 816. DOI: $10.29252 /$ johe.5.4.8

\section{Abstract}

Background and Objective: In the last few decades, organizational factors have become the leading indicators of occupational health and safety (OHS) performance in industries. ELMERI is a simple and cost-effective method for monitoring OHS performance in the manufacturing industries. Regrading this, the present study was carried out to evaluate the safety and health performance in a steel industry by using the ELMERI index.

Materials and Methods: In this cross-sectional descriptive study, the safety and health conditions of the workplace were evaluated by Health and Safety Executive (HSE) specialists using the ELMERI index. The ELMERI index covered safety behavior, workplace hygien and housekeeping, machinery safety, occupational health, ergonomics, walkways, fire safety, and first aids. Finally, ELMERI index was examined based on the findings.

Results: The results of this study demonstrated that an ELMERI index of $69 \%$ is indicative of a moderate performance. Safety behavior, workplace hygien and housekeeping, machinery safety, occupational health, ergonomics, walkways, fire safety, and first aids were determined as $75 \%$, $64.4 \%, 80.5 \%, 51.4 \%, 66 \%, 75 \%$, and $79.6 \%$, respectively.

Conclusion: A common feature for goal setting and a real-time indication of OHS performance is the use of the ELMERI method. The ELMERI method fills the gap between management activities and accident-based indicators in OHS management systems. The results of this study enable managers to make the best decisions to provide and implement preventive measures based on indicators and events by the evaluation of performance safety.

Keywords: ELMERI Index, Safety and Health Performance; Steel Industry 


\section{ارزيابى عملكرد ايمنى و بهلاشت براساس شاخص ELMERI در يكى از صنايع فولاد استان خوزستان}

روحالله كاظمى'، ليلا نعمت يور '، سيد امين جزايرى r.*

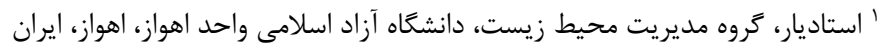

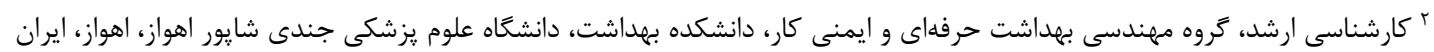

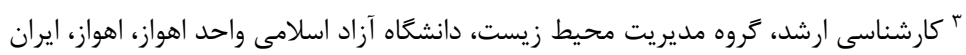
* نويسنده مسئول: سيد امين جزايرى، كروه مديريت محيط زيست، دانشخاه آزاد اسلامى واحد اهواز، اهواز، ايران. ايميل:Aminj.hse57@gmail.com

\section{קكيده}

سابقه و هدف: در جند دهه كَذشته عوامل سازمانى در ايمنى كار به شاخصهاى ييشرو در تشريح عملكرد

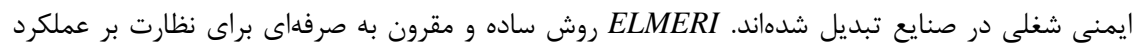

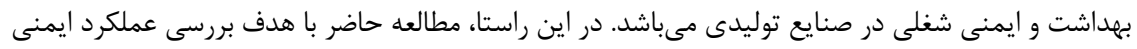

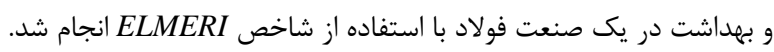
مواد و روشها: در اين مطالعه توصيفى- مقطعى، وضعيت ايمنى و بهداشت توسط كارشناسان

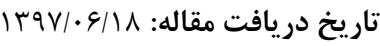

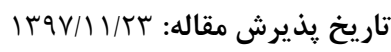
تمامى حقوق نشر براى دانشعاه علوم (Health and Safety Executive)

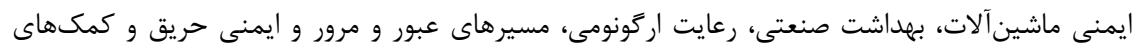

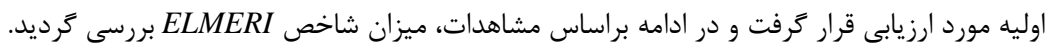

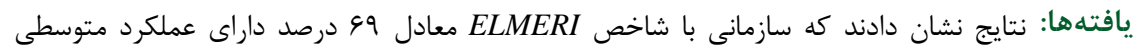

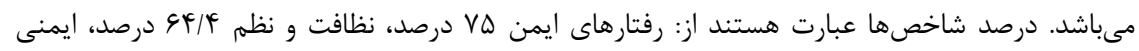

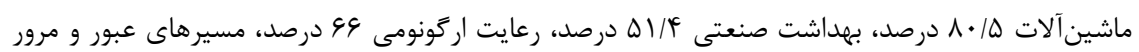

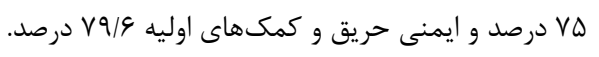

نتيجه كيرى: يكى از ويزَى هاى رايج، استفاده از روش

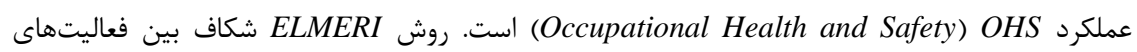

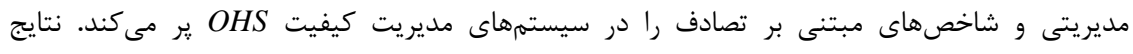

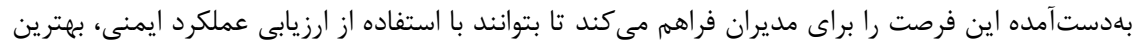

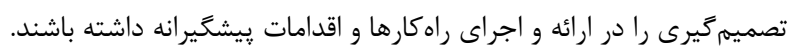

حوادث را تا حدودى كاهش دهند؛ اما در نهايت موفقيتآميز

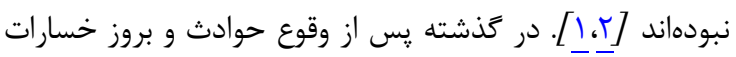

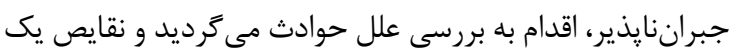

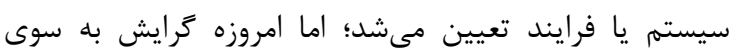

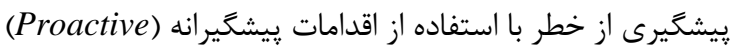

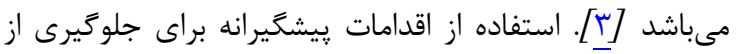

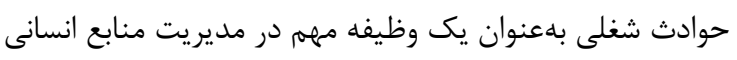

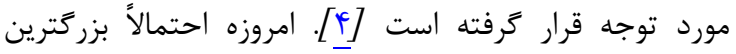
مشكلى كه مديريت ايمنى و بهداشت شغلى با آن مواجه است،
مقلدمه

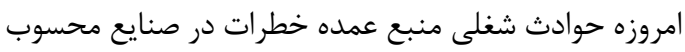

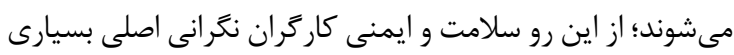

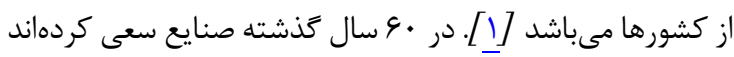

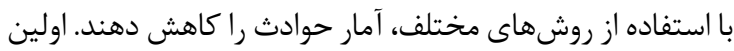

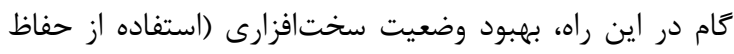

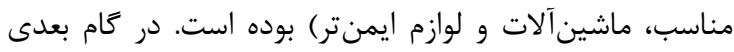

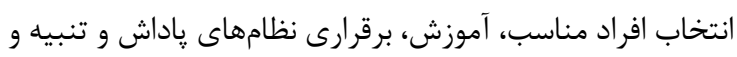

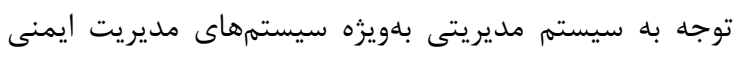

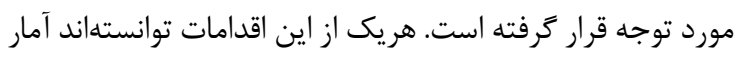




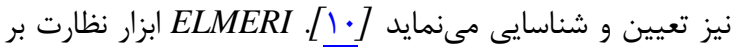

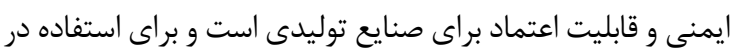

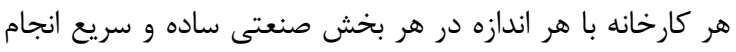

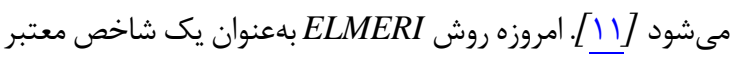

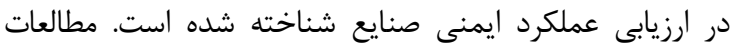

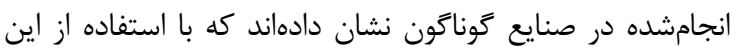

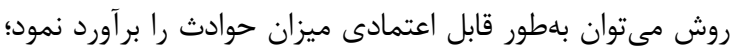

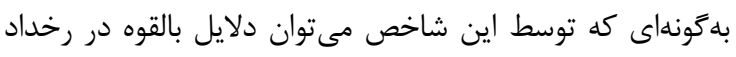

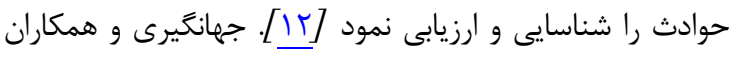

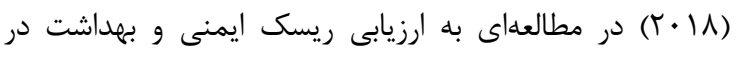

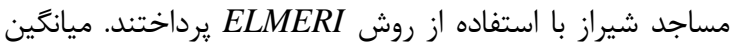

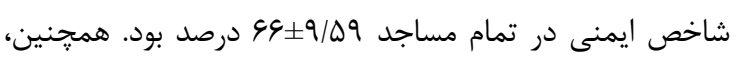

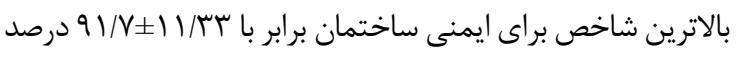

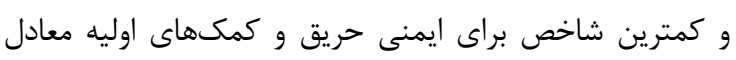
همكاران (Y/T

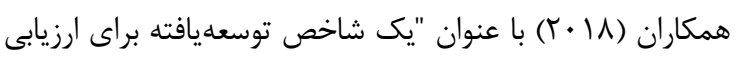

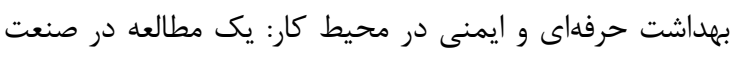

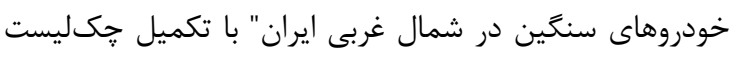
ELMERI سلسلهمراتبى (AHP: Analytical Hierarchy Process) به دانه

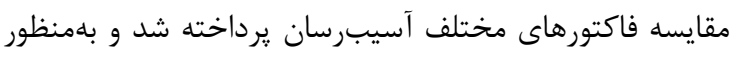

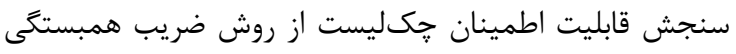
درون كروهى (ICC: Intra-class Correlation Coeffcient)

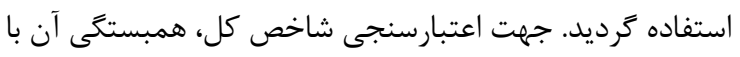

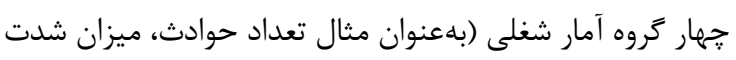

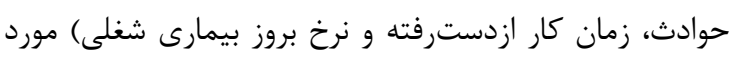

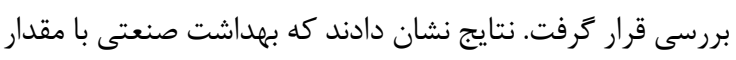

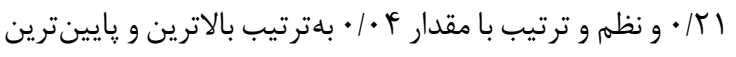

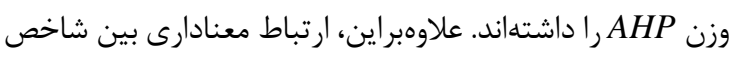

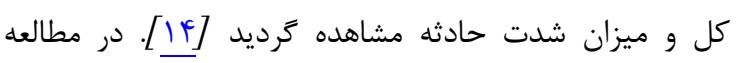
و همكاران (Ylitinen

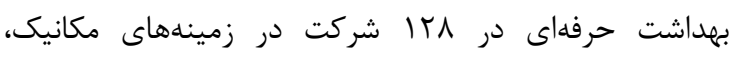

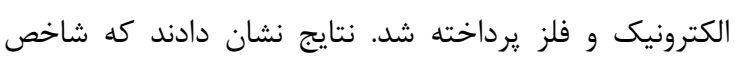
ELMERI

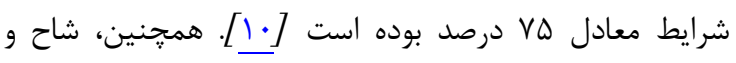

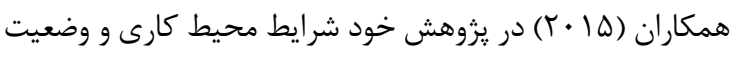

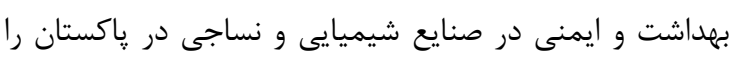

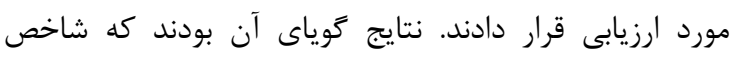

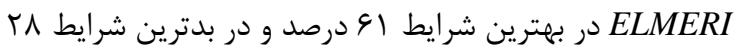

$$
\text { درصد بوده است [11] }
$$

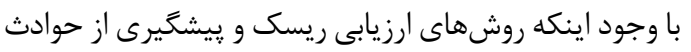

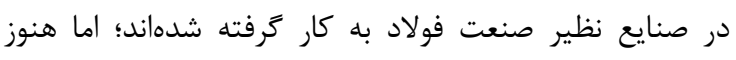

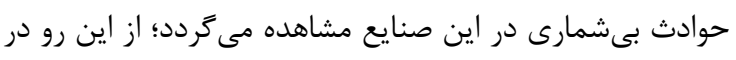

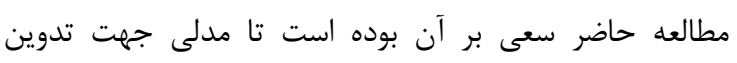

فقدان شاخصهاى پيشكَيرانه اثركذار بر ارزيابى عملكرد ايمنى و

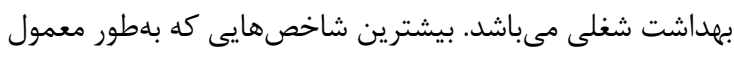

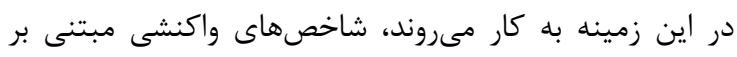

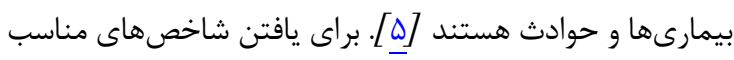

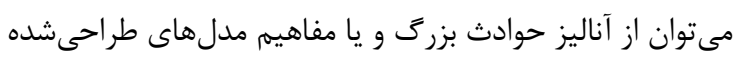

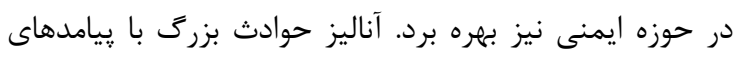

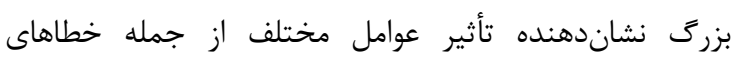

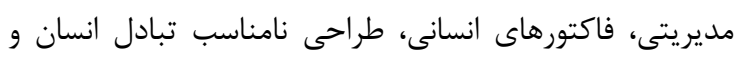

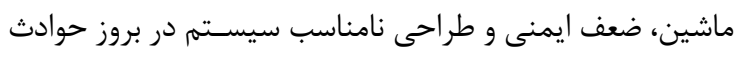

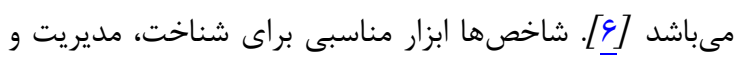

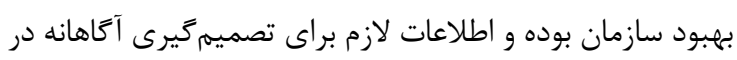

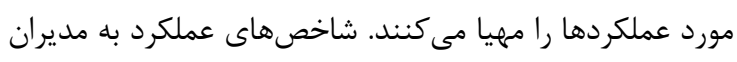

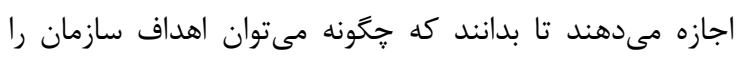

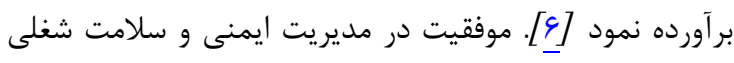

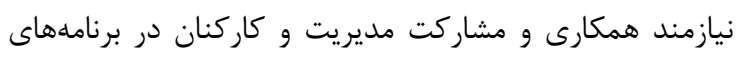

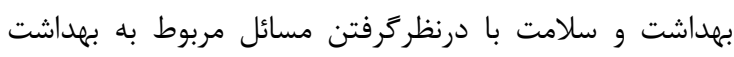

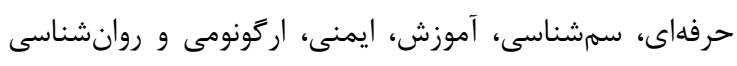

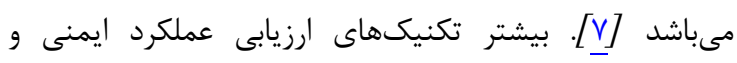
بهداشت شغلى (OHS: Occupational Health and Safety)

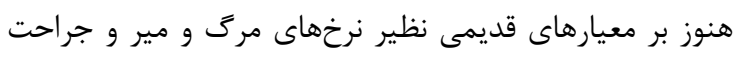

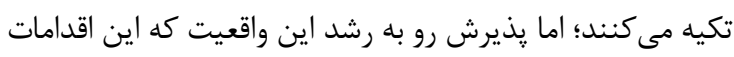

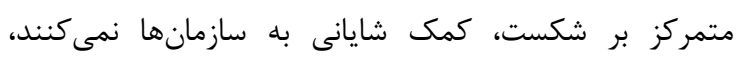

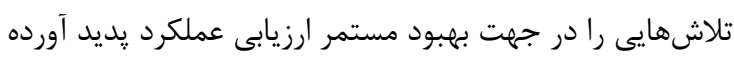

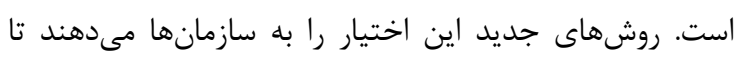

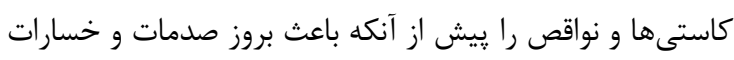

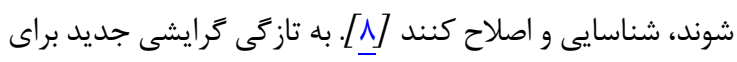

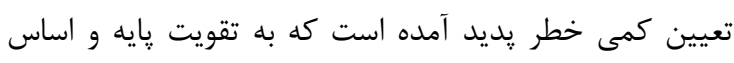

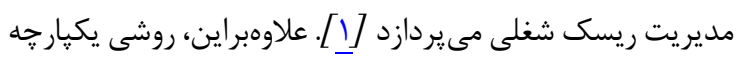

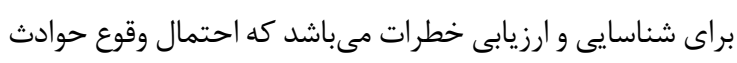

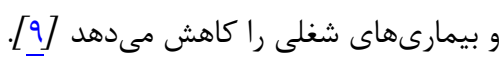

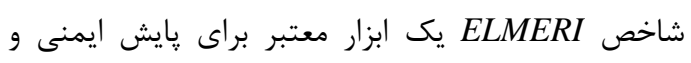

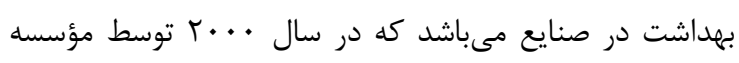

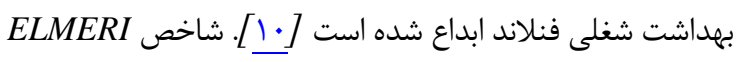

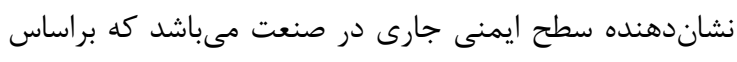

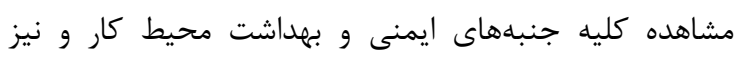

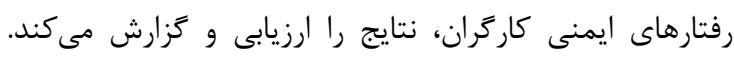

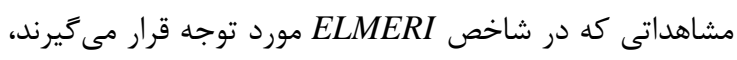

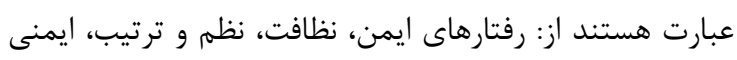

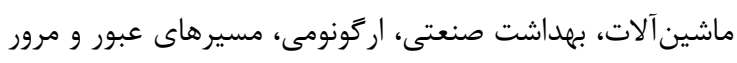

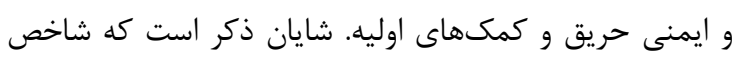

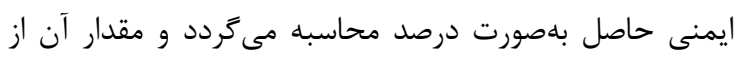

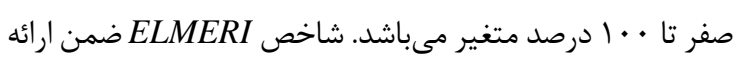

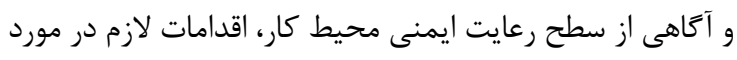

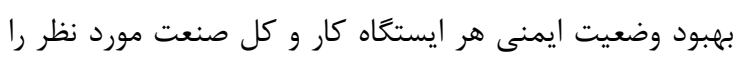


ارزيابى ارگونومى، شناسايى و ارزيابى مسيرهاى عبور و مرور،

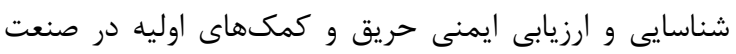

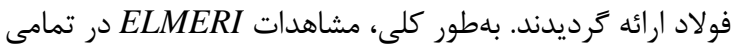

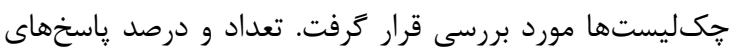

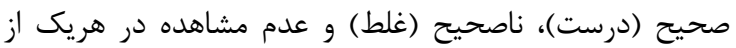
سؤالات فرم مشاهدات ELMERI تعيين گرديد. ناهح بهنظور سنجش عملكرد HSE با استفاده از روش رئس ELMERI زير بوده است.

روش ELMERI براساس مشاهده كليه جنبههاى ايمنى و بهداشت محيط كار و رفتارهاى ايمنى كارگران مئباشد. مشاهداتى كه در شاخص ELMERI مورد توجه قرار كرفتهاند، شامل هفت مورد زير مىباشند:

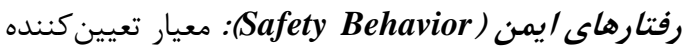

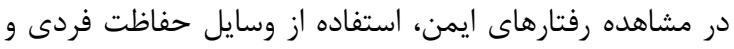

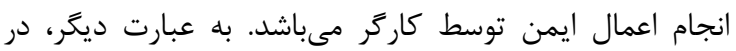
صورتى كه كارگر حين انجام كار از وسايل حفاظت فردى مهى مورد نياز با توجه به نوع خطرات موجود استفاده نمايد و از انجام اعمال

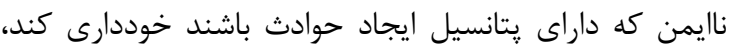

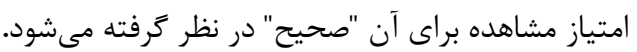

\section{نظافت و نظمر و ترتيب ( Workplace Order and} SHousekeeping كار، قفسهها، سطوح ماشين آلات و يا حتى ظروف زباله موجود در

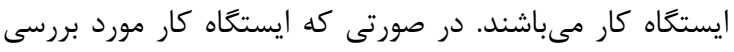

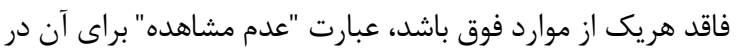

$$
\text { نظر زرفته مىشود. }
$$

ايمنسى ماشينآلات (Machinery Safety): شامل: طراحى، ساخت و شرايط ماشينآلات موجود در ايستخاه كار،

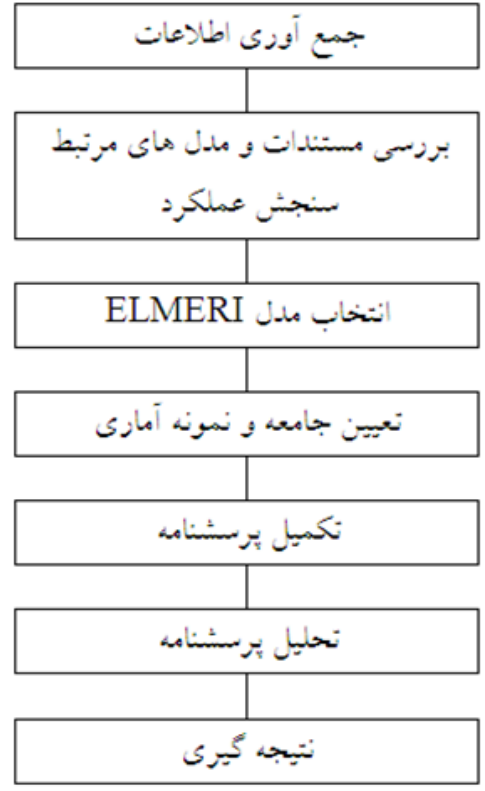

شكل ا: مراحل קيادهسازى تكنيك ELMERI
شاخصهاى ارزيابى عملكرد سيستم مديريت ايمنى تدوين گردد

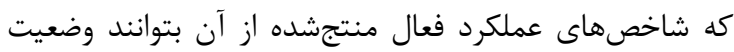
ايمنى در تمامى سطوح عمليات كار در صنعت فولاد را تعيين

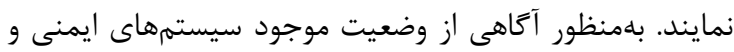

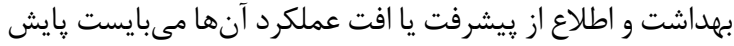

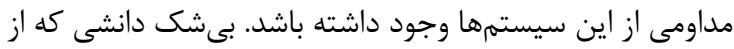

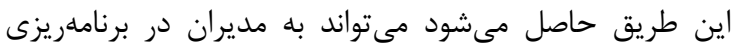

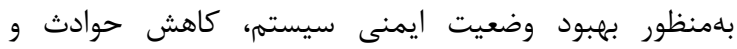

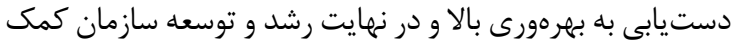

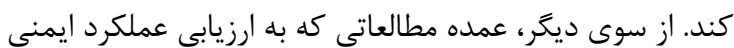

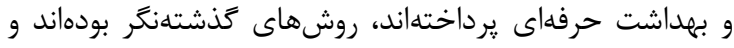

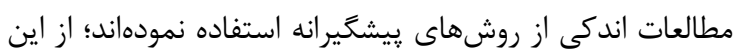

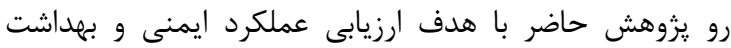
براساس شاخص ELMERI در يك صنعت فولاد انجام شد تا بتوان كاستىهاى موجود در اين صنعت را بررسى نمود و به ارائه

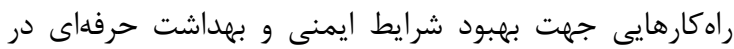

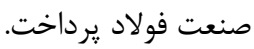

\section{مواد و روشها

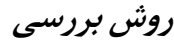

مطالعه حاضر از نوع توصيفى - مقطعى مىباشد. جامعه آمارى

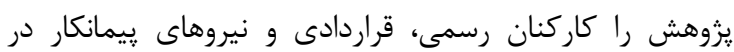

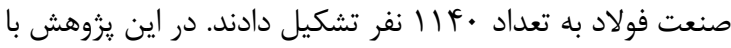

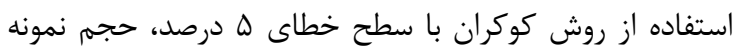

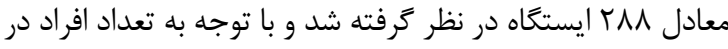
هر واحد، تعداد ايستخاههاى مورد بررسى بلهدست آمد (رابطه ل) ():

$$
n=\frac{\frac{z^{2} p q}{d^{2}}}{1+\frac{1}{N}\left(\frac{z^{2} p q}{d^{2}}-1\right)}
$$

واحدهاى مورد بررسى در اين مطالعه شامل هشت واحد

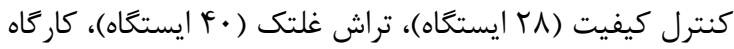

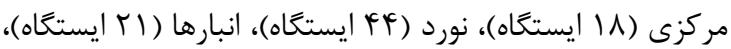

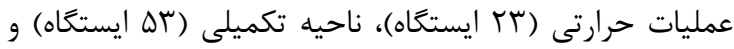

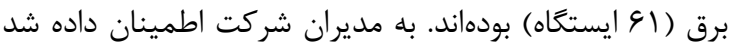

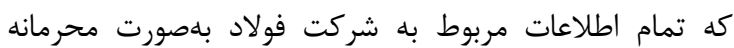

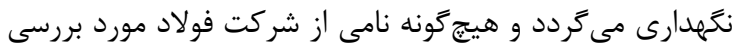

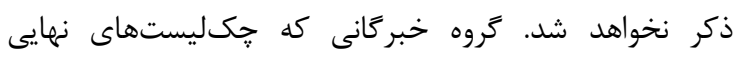
شاخصها را تكميل نمودند، شامل مسئولان ايمنى كارفرما و

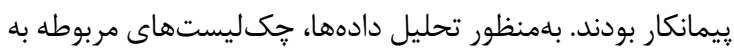

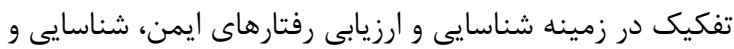

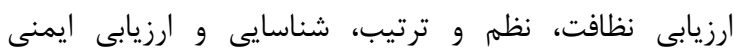
ماشينآلات، شناسايى و ارزيابى بهداشت صنعتى، شناسايى و ورئ، 
دستورالعمل ELMERI بيان شدهاند در مورد آنها رعايت شده

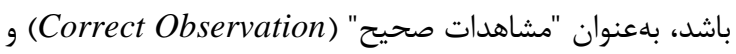
در غير اين صورت بهعنوان "مشاهدات ناصحيح" ( Incorrect (Observation

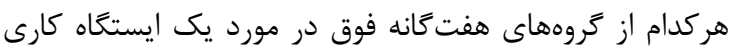

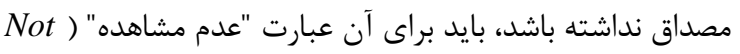

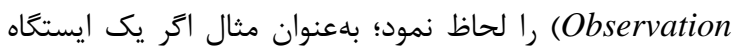

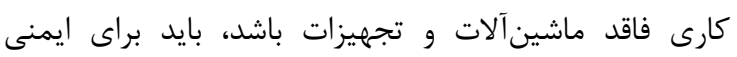

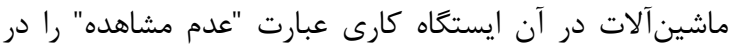

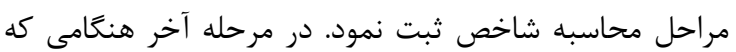

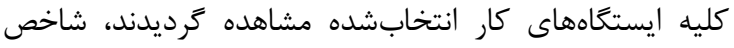
ELMERI ELMERI

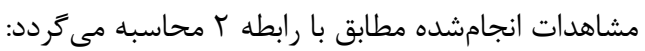
رابطه

$$
\text { ELMERI }=\frac{\text { Correct }}{\text { Correct }+ \text { Incorrect }} \times 100
$$

تجزيه و تحليل آمارى با استفاده از نرمافزار SPSS 22 صورت

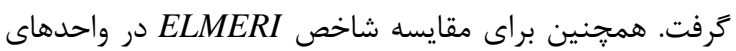
مختلف از آزمون ANOVA يكسرفه استفاده كرديد. سطح

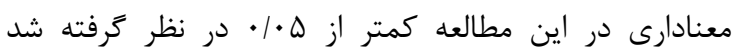

\section{بافته.}

براساس خروجى نظر خبركان و با استفاده از رابطه r بيانشده در روش كار، يك شاخص بلهدست مى نى آيد كه

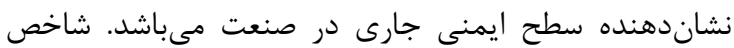

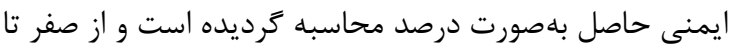

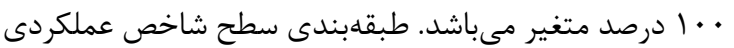

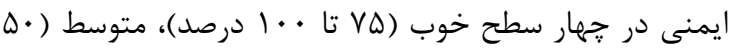

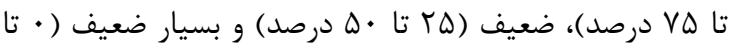

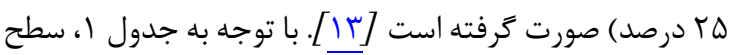
ايمنى در هر واحد بررسى شده و نتايج گوياى آن هستند كه

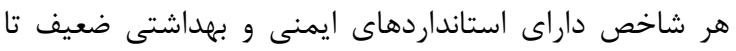

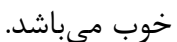
همان كونه كه در جدول ا مشاهده مىشود، سطح عملكردى

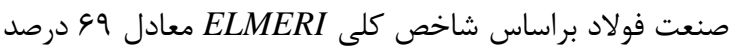

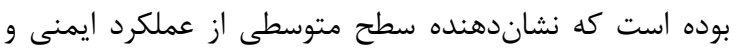
بهداشت مىباشد. شاخص كلى در واحد نورد داراى بيشترين

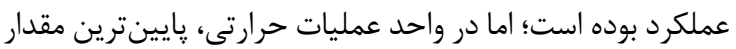

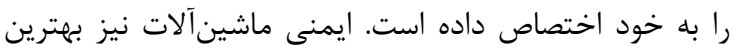

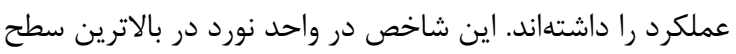
بوده است؛ بنابراين مىتوان كفت كه سطح عملكردى خوبى
وسايل كنترلى و متوقف كنندههاى اضطرارى، حفاظ ماشين آلات

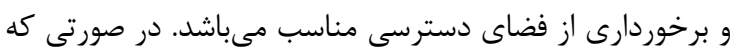

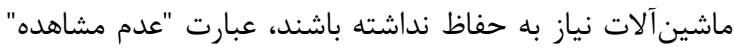
براى آن در نظر زرفته مىشود.

\section{بهداشت صنعتى (Occupational Health): عوامل}

زيانآور شامل: صدا، روشنايى، كيفيت هوا، شرايط جوى و مواد

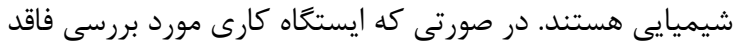

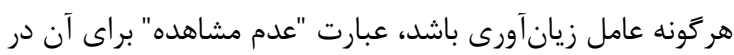
نظر كرفته مى شونه عامل زيان.

اركونومسى (Ergonomics): معيارهاى تعيين كننده در در

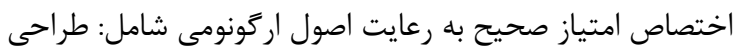

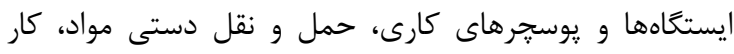

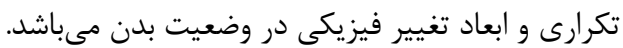

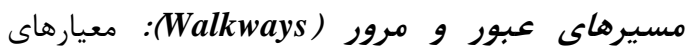

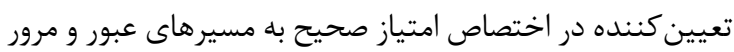

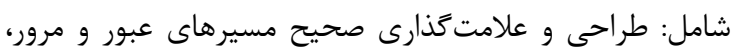

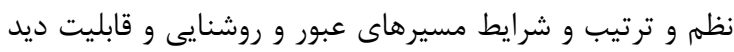
مسيرهاى عبور مىباشد.

Fire Safety and (يمنى حريق و كمكهاى اوليه First Aids به ايمنى حريق و كمكهاى اوليه عبارت هستند از: تابلوهاى برق،

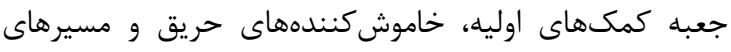

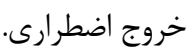
ELMERI مراحل انجام مرحله اول شناسايى كليه مشاغل موجود در صنعت

مرحله دوم: انتخاب / يستتاهماى كار

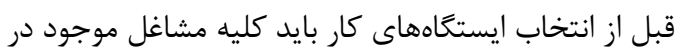

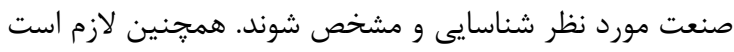

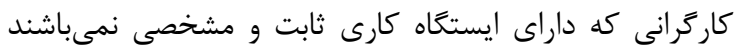
(ماند نظافتجيان و رانندگان ليفتراك) مورد مشاهده قرار كيرند.

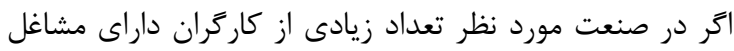

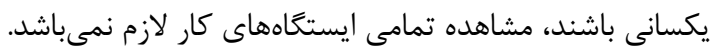

مرحله سوم: مشاهده /يستغاههاى كار بر مبناى ELMERI شاخصهاى رفتارهاى ايمن، نظافت، نظم و ترتيب، ايمنى ماشين آلات،

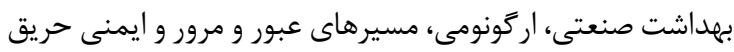
و كمكهاى اوليه جهت محاسبه شاخص ELMERI ابتدا لازم است كليه موارد فوق در هر ايستگاه كارى كه براى ارزيابى انتخاب

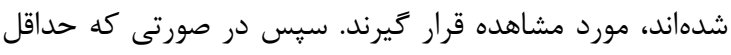

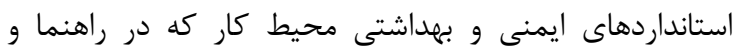


جدول ا: ارزيابى شاخصهاى عملكرد ايمنى و بهداشت واحدهاى مختلف

\begin{tabular}{|c|c|c|c|c|c|c|c|c|c|c|}
\hline $\begin{array}{c}\text { شاخص } \\
\text { ElMERI }\end{array}$ & كيفتيت & غراش & مركز كاه & 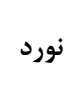 & 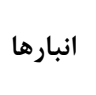 & عرارتى عمليات & تكميلى & برق & واحدها & صنعت فولاد \\
\hline Va & FT/AD & $v \Delta$ & $V T / V$ & $\Lambda V / \Delta$ & 4. & $V \Delta$ & $\Lambda \Delta / V I$ & $\Lambda \cdot 19$. & رفتارهاى ايمنى & \\
\hline$G \varphi / 4$ & $\forall \wedge / r \Lambda$ & $s \varphi / \Delta \Lambda$ & $\Delta V / V$ & $v 1 / \cdot r$ & $v \cdot / \Delta$ & $\Delta \Lambda / \Lambda$ & $s \varphi / 4$ & $V \Psi / 9$ & نظافت و نظه & \\
\hline$\Lambda \cdot 10$ & 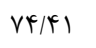 & $\Lambda T / V$ & $11 / 1$ & $\Lambda \vee / \Lambda$ & VQ & $9 \Delta / V$ & $19 / \pi 4$ & $\wedge 9 / 9$ & ايمنى ماشينآلات & شاخصهاي \\
\hline$\Delta 1 / \kappa^{\circ}$ & $\Delta \Delta / r$ & $\Delta \varphi$ & GK/G & $s 4 / \Lambda$ & $f \mid / \Delta \Lambda$ & Tr/AD & $\Delta \cdot$ & FV/TV & بهداشت صنعتى & \\
\hline 99 & $q \mu / \Lambda$ & $9 \Lambda$ & $V r / 4 \varepsilon$ & 99199 & 99199 & $\Delta I / F T$ & $G N / D I$ & $S V / T V$ & ر رعايت اركونومى & ELMERI \\
\hline VQ & VG/9T & $V V / V V$ & VT/VT & $v e / 19$ & $V V / \Delta$ & $\Delta \Lambda / \cdot 9$ & $\Lambda \Gamma / \Delta$ & $\Lambda F / \cdot q$ & مسيرهاى عبور و مرور & \\
\hline$\vee 9 / 9$ & $V G / F V$ & $V T / T T$ & $V \cdot / 9 V$ & $\Lambda T / 9$ & $\Lambda \Delta / F T$ & $\mathrm{Vq} / \cdot \mathrm{V}$ & $\wedge$. & $\Lambda \mu / \cdot \Lambda$ & ايمنى حريق و كمكهاى اوليه & \\
\hline 99 & GF/VT & $V \cdot / \pi r$ & $V \cdot / r$ & $V F / \Lambda$ & $94 / T$ & $\Delta 9 / 9$ & $V \backslash / 4$ & VF & & شاخص كل واح \\
\hline
\end{tabular}

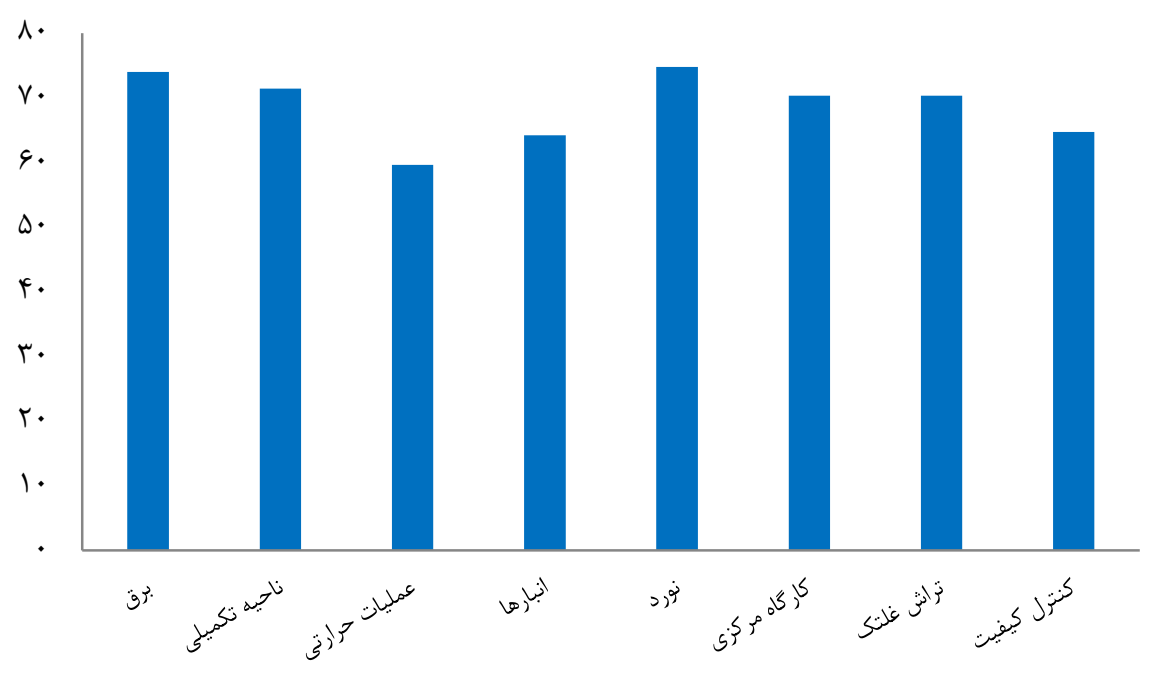

شكل r: شاخصهاى ارزيابى عملكرد ايمنى واحدها

نداشته است (ه • • (P>).

\section{بحث}

مطالعه حاضر با هدف ارزيابى عملكرد ايمنى و بهداشت

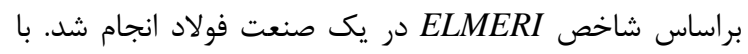
توجه به ميزان شاخص ELMERI محاسبهشده در واحدهاى

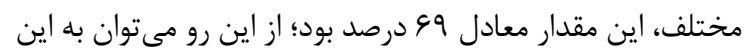

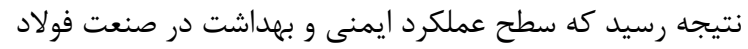

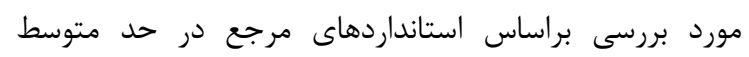

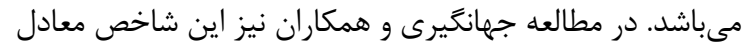

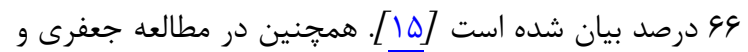

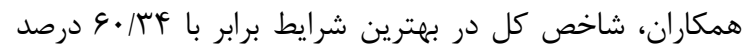

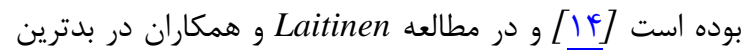

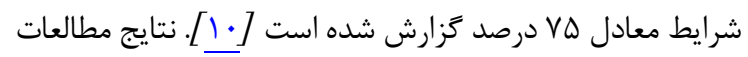

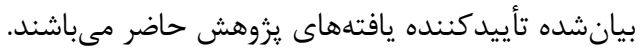

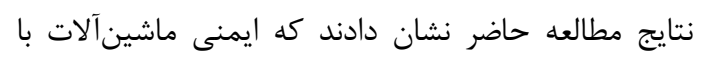

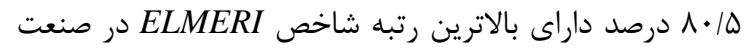

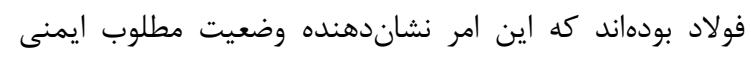

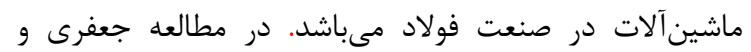
همكاران نيز اين شاخص در شرايط مناسبى قرار داشت و با نتايج
داشته است؛ اما همين شاخص در عمليات حرارتى كمترين مقدار

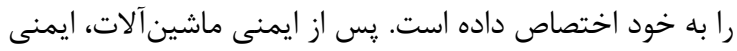

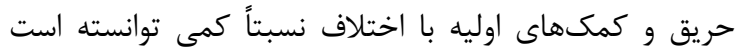

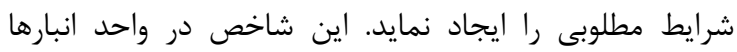

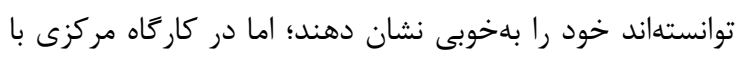

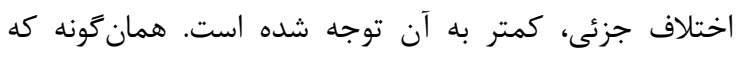

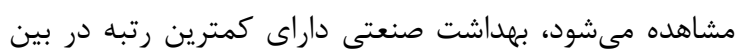

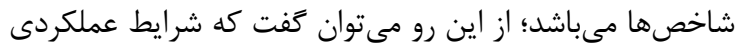
ضعيفى داشته است؛ بهطورى كه در واحد انبارها، بهداشت إنت

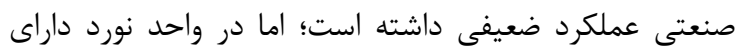
شرايط تقريباً متوسطى بوده است. شاخصهاى عملكردى بهطور كلى اطلاعات مهمى را درباره

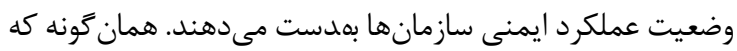
در شكل r مشاهده مىشود، شاخصهاى

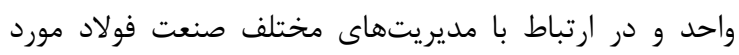

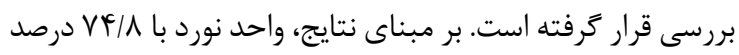

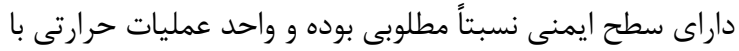

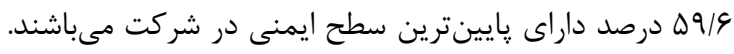

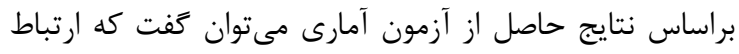

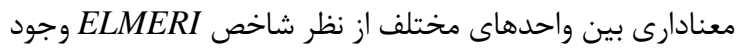


نتايج حاصل از اين مطالعه نشان دادند كه ارائه آموزشهاى ايمنى

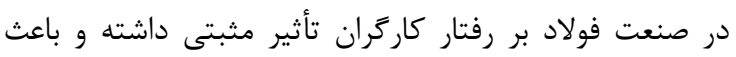
افزايش رتبه رفتار ايمن در اين شركت شده است. برخى از

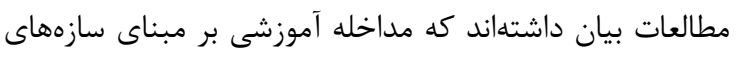

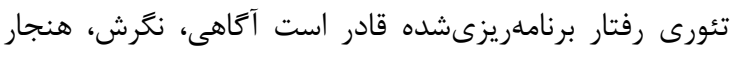

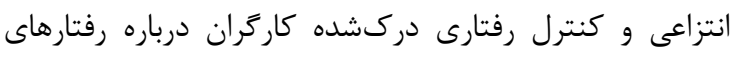

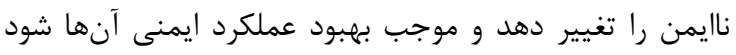

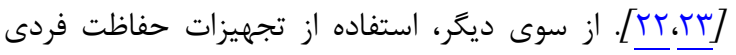

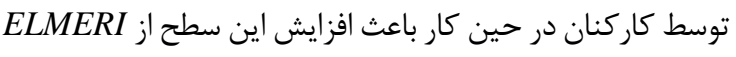

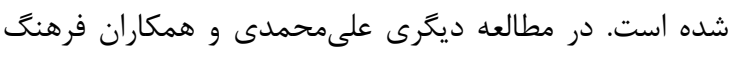

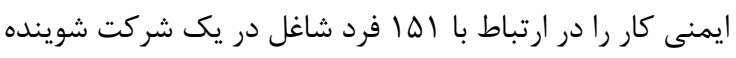
و ياك كننده مورد بررسى قرار دادند. در اين مطالعه با توجه بـ ارديه

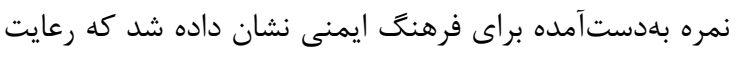

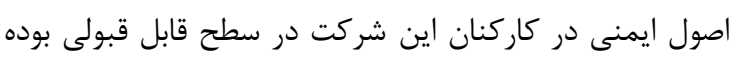

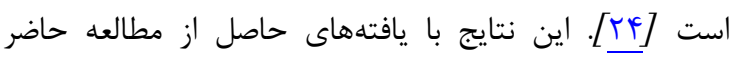

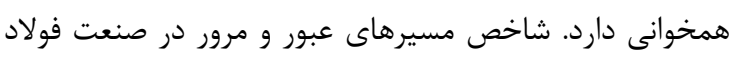

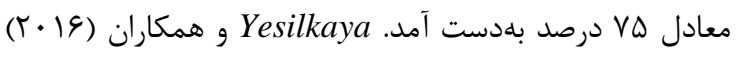

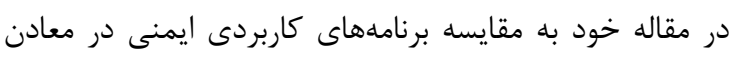

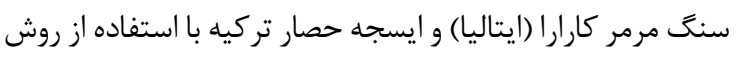
ELMERI توجه به روش ELMERI تجزيه و تحليل شدند و شاخصهاى

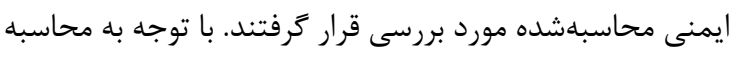

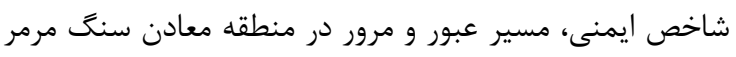

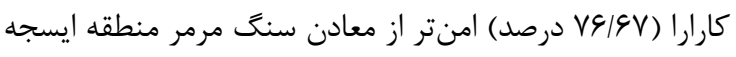
حصار (\$V/

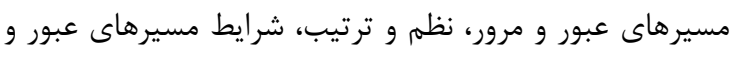

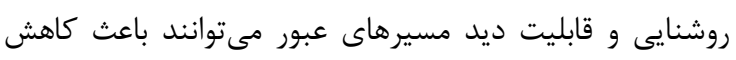
حوادث ترافيكى شوند. صنعت فولاد با استفاده از اين تمهيدات

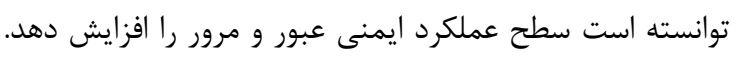
بر مبناى نتايج، رعايت اصول ارگونومى در صنعت فولاد معادل

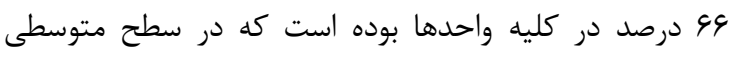
مىباشد. در اين ارتباط، نتايج مطالعه Laitinen و همكاران نشان

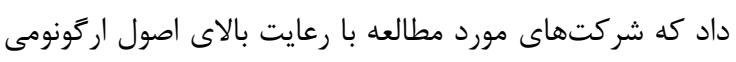

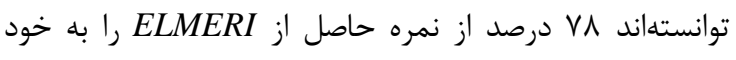

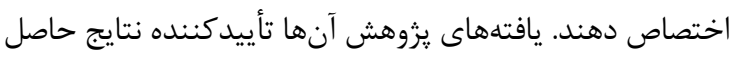

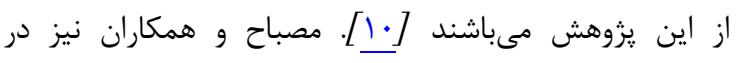

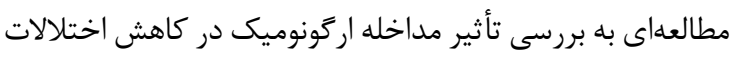

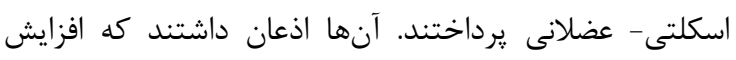

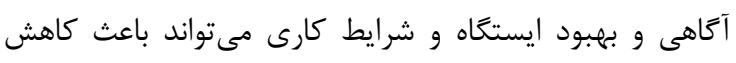

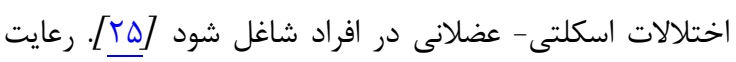

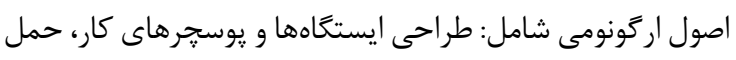

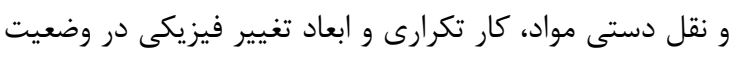

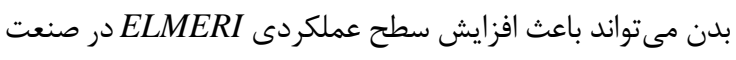

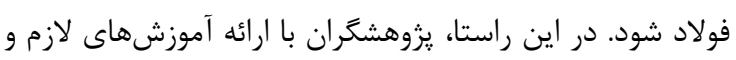

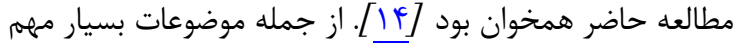

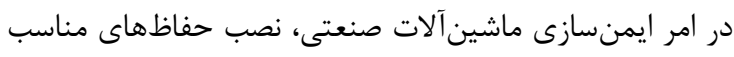

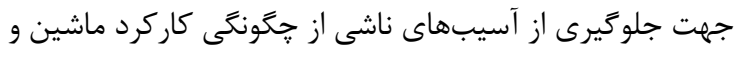

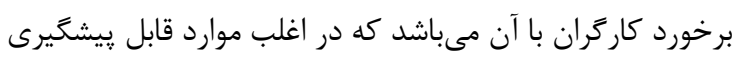

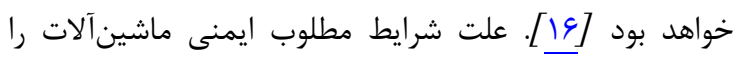

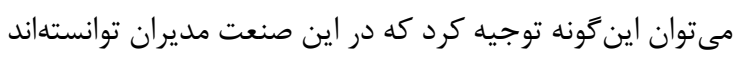

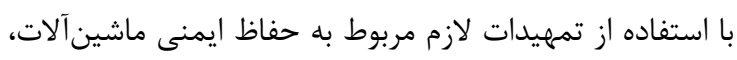

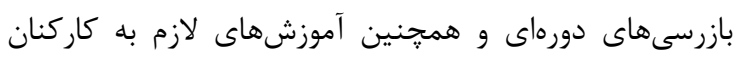

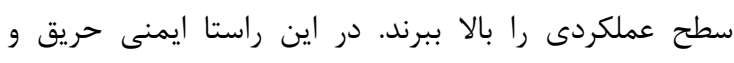

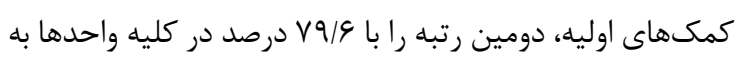

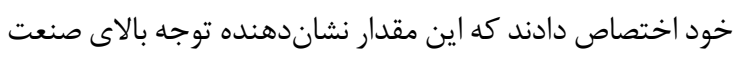

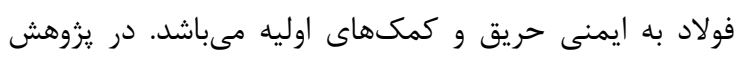
Nordlöf

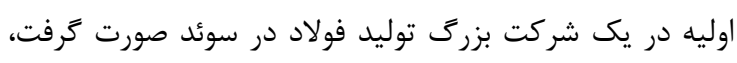

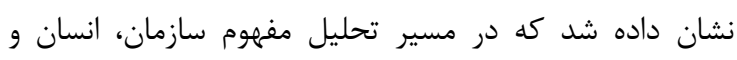

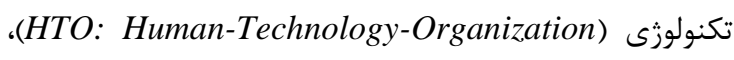

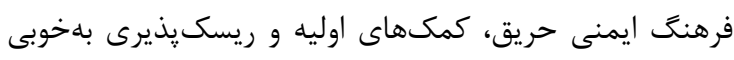

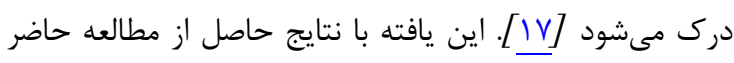
همسو مىباشد. از سوى ديگر، در مطالعه راستانى و همكاران

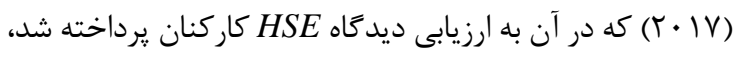
نتايج نشان دادند كه ايمنى حريق و كمكهاى اوليه در سطح ضعيفى قرار دارند كه علت آن كمبود علائم و يوسترهاى ايمنى وادئ

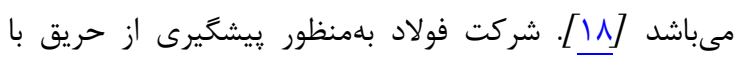

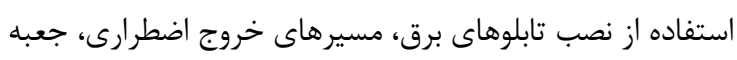

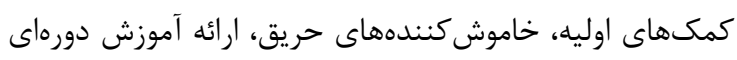

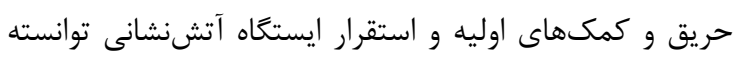
است اين عملكرد را ارتقا بخشد. با توجه به نتايج، رفتارهاى إئ ايمن

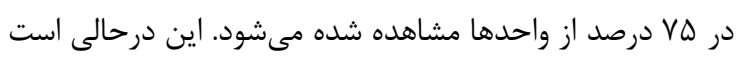

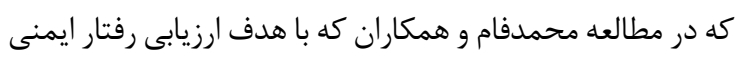

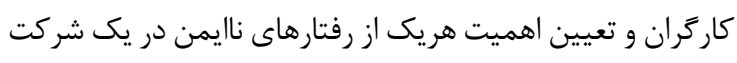

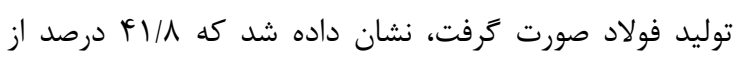
رفتارهاى كارگران نايمن مىباشد. در اين راستا، شايعترين رفتار

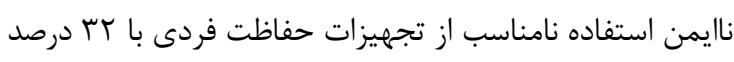

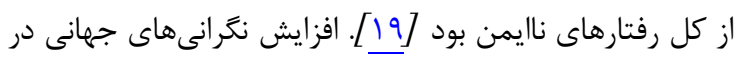

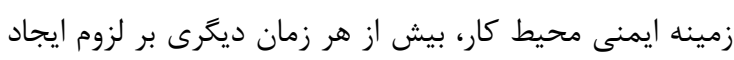

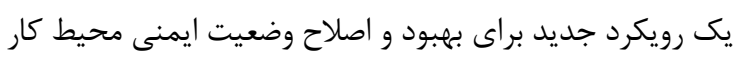

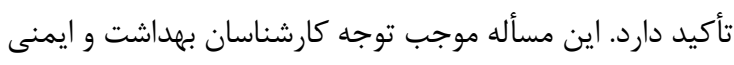

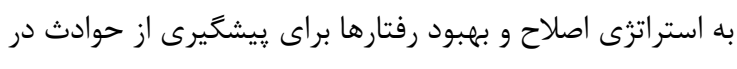

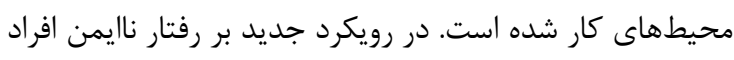

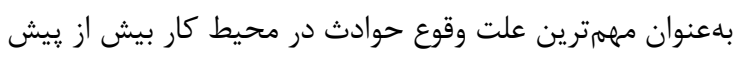

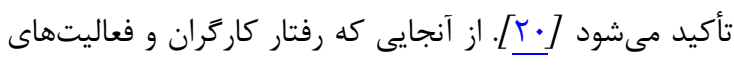
كارى در بسيارى از حوادث دخيل هستند، ارائه آموزش بـ به آنهائ

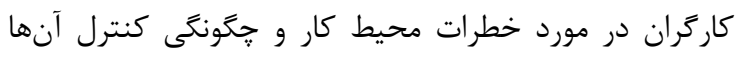

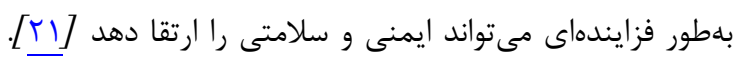


همراه با اين روش، امرى ضرورى مىباشد. از محدوديتهاى ديگر

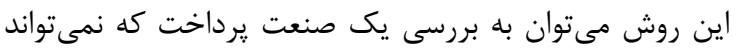

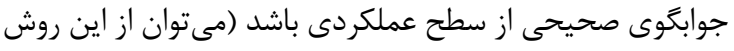

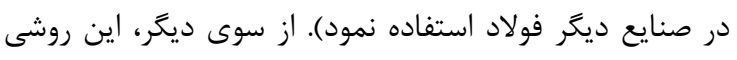

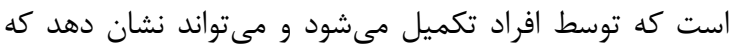

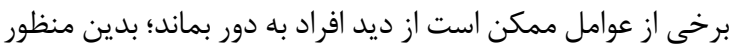
بيشنهاد مىشود كه موارد ذكرشده در مطالعات آتى مورد توجه قرار گيرند.

\section{نتيجه}

مطالعه حاضر با استفاده از يك شاخص فعال (آيندهنگر) و

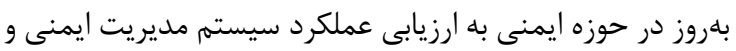

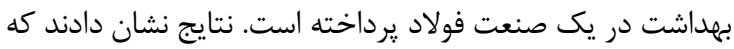

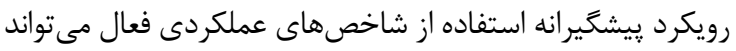

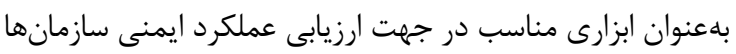

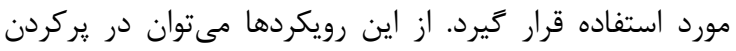

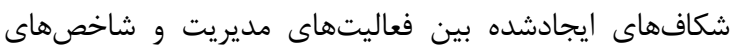
مبتنى بر حوادث در سيستمهاى مديريت OHS استفاده نمود. باديا

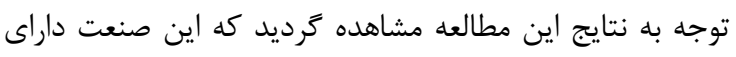
عملكرد ايمنى و بهداشتى متوسطى مىباشد. همجنين، نتايج

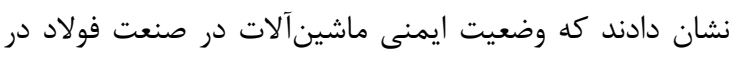

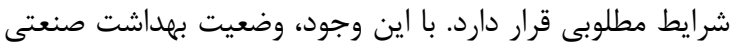

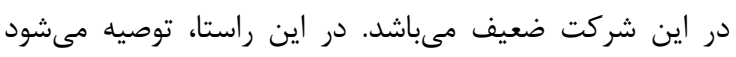
مديران شركت نسبت به اين موضوع توجه ويزهاى داشته باشند.

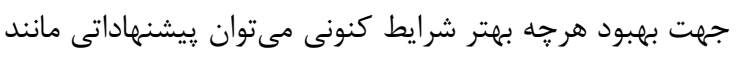

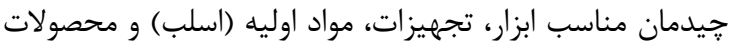

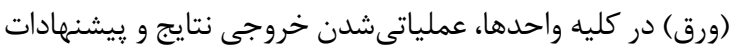

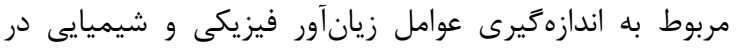

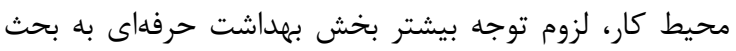

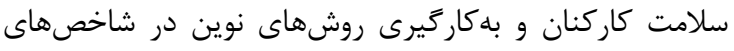
حوزه سلامت كاركنان را ارائه نمود.

\section{تشك و قنروانى}

اين مقاله بخشى از يايانامه دانشجويى آقاى جزايرى به

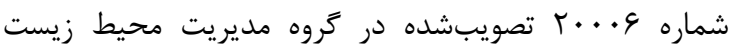

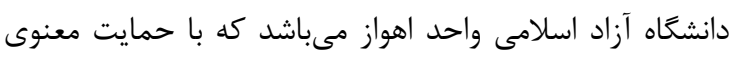

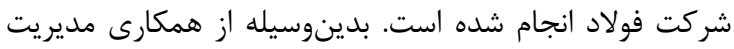

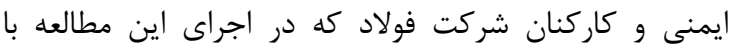

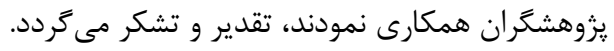

\section{REFERENCES}

1. Aneziris ON, Topali E, Papazoglou IA. Occupational risk of building construction. Reliab Eng Syst Safety. 2012;105:3646. DOI: 10.1016/j.ress.2011.11.003

2. Sinelnikov $S$, Inouye J, Kerper $S$. Using leading indicators to measure occupational health and safety performance. Safety
استفاده از وسايل و تجهيزات الكتريكى جهت حمل و نقل مواد

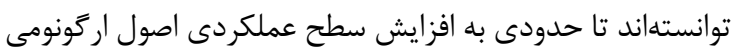

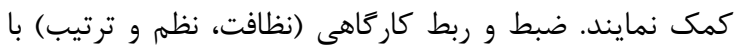

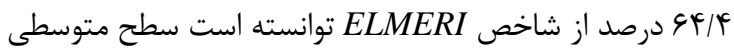
از عملكرد ايمنى در سازمان را به خود اختصاص دهد. محمدفام

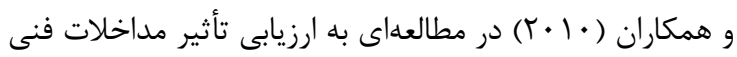

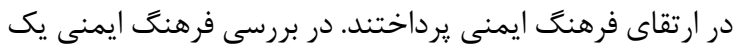

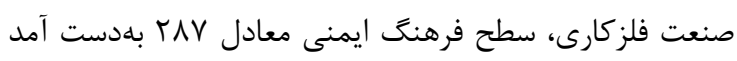

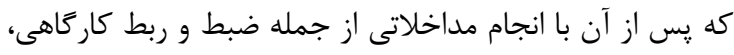

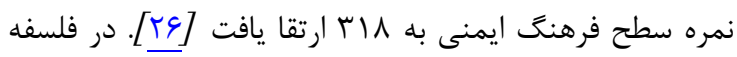
زاينىها، ضبط و ربط معادل نظام آراستخىى (5S) در نظر كرفته

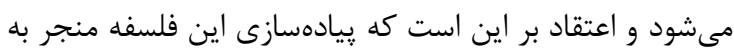

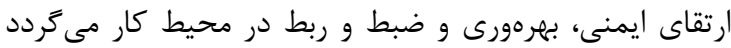

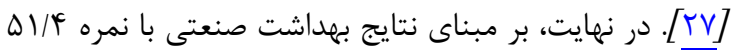

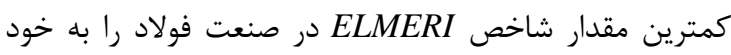

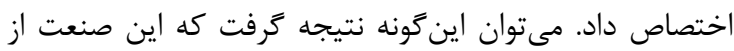
نظر بهداشت صنعتى در سطح نسبتاً ضعيفى قرار دارد. در مطالعه إنه

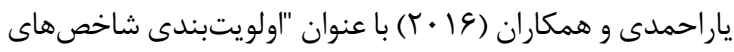

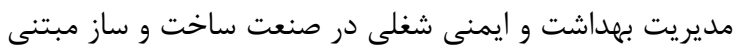

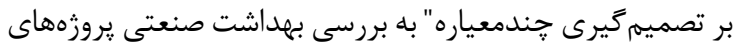

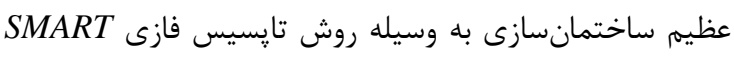
(Specific, Measurable, Achievable, Realistic Timely) يرداخته شد. نتايج گَوياى آن بودند كه بهداشت صنعتى از نظر

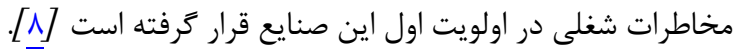

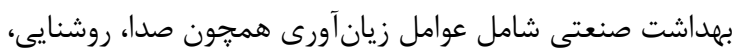

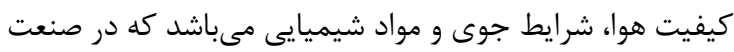

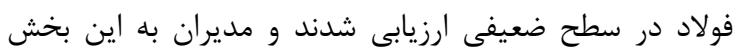

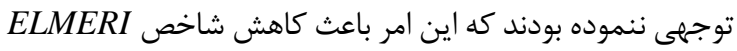

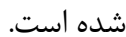

همجون مطالعات ديكر، يزوهش حاضر نيز داراى نواقصى بود

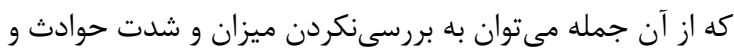
تأثير آنها بر عملكرد سازمان اشاره نمود. ديخر محدوديت اين

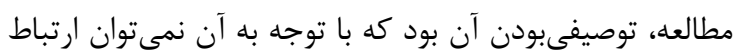

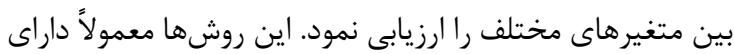

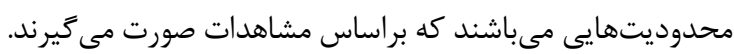

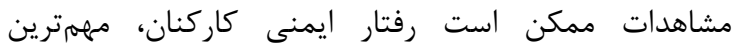
خطرات احتمالى، عوامل خطرساز اسكلتى - عضلانى و همجنين

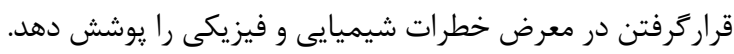

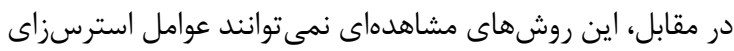

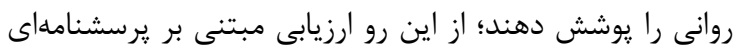

Sci. 2015;72:240-8. DOI: 10.1016/j.ssci.2014.09.010

3. Wang $Y$, Tian M, Wang D, Zhao Q, Shan S, Lin S. Study on the HSE management at construction site of oil and gas processing area. Procedia Eng. 2012;45:231-4. DOI: 10.1016/j.proeng.2012.08.149 
4. Ersoy M, Yesilkaya L. Comparison of the occupational safety applications in marble quarries of Carrara (Italy) and Iscehisar (Turkey) by using Elmeri method. Int J Inj Contr Saf Promot. 2016;23(1):29-63. PMID: 25358899 DOI: 10.1080/17457300.2014.945464

5. Halsti E. Työn kuormitus nuorten aikuisten kokemana. Kirjaudu: Liiketalouden koulutusohjelma; 2013.

6. Barkhordari A, Dehghani A, Kianfar A, Mahmoudi S, Aminifard F. Safety performance evaluation using proactive indicators in a selected industry. J Occup Hyg Eng. 2015;1(4):49-59. [Persian]

7. Frank T, Brooks S, Creekmore R, Hasselbalch B, Murray K, Obeng $K$, et al. Quality risk management principles and industry case studies. Pharm Qual Res Inst Manuf Technol Comm. 2008;28:1-9.

8. Yarahmadi R, Shahkohi F, Taheri F, Moridi P. Priority of occupational safety and health indexes based on the multi criteria decision making in construction industries. Iran Occup Health. 2016;12(6):39-47. [Persian]

9. Zaikina D. Development of the unified technique for the monitoring of occupational hazards at Kryvbas mining enterprises (Ukraine). East Euro J Enterprise Technol. 2017;3(10):18-27. DOI: 10.15587/1729-4061.2017.101657

10. Laitinen $H$, Vuorinen $M$, Simola A, Yrjänheikki $E$. Observation-based proactive OHS outcome indicatorsvalidity of the Elmeri+ method. Safety Sci. 2013;54:69-79. DOI: 0.1016/j.ssci.2012.11.005

11. Shah N, Abbas F, Abbas Y, Haider SA, Khan Q, Asghar N, et al. Assessment of the workplace conditions and health and safety situation in chemical and textile industries of Pakistan. Science. 2015;3(6):862-9. DOI: 10.11648/j.sjph.20150306.20

12. Jahangiri MR, Nowroozi A, Mohammad A. Management and risk assessment. Tehran: Fanavaran Publishing; 2015.

13. Jahangiri $M$, Ghaedi $S$, Dianatkhah $S$, Khademi $S$, Hassanipour $S$, Kamalinia $M$, et al. Safety and health risk assessment in mosques, Shiraz, Iran. Shiraz E Med J. 2018;19(12):e68926. DOI: 10.5812/semj.68926

14. Jafari A, Choobineh A, Jahangiri M, Keshavarzi S. An index developed for the assessment of occupational health and safety at workplace: a field study in a heavy automotive industry in the northwest of Iran. J Health Sci Surveillance Syst. 2018;5(2):86-93

15. Malakoutikhah M, Korouni H, Jahangiri M. Safety and health status of educational and research laboratories of Shiraz University of medical sciences based on ELMERI approach. Occup Hyg Health Prom J. 2019;2(4):270-9. DOI: 10.18502/ohhp.v2i4.436

16. Mououdi MA. Designing an industrial machine guard. J Ergon. 2015;3(3):38-43.

17. Nordlöf $H$, Wiitavaara $B$, Winblad $U$, Wijk $K$, Westerling $R$. Safety culture and reasons for risk-taking at a large steelmanufacturing company: investigating the worker perspective. Safety Sci. 2015;73:126-35. DOI: 10.1016/j.ssci.2014.11.020

18. Jamshidi Rastani M, Biganeh J, Ayoubitalab M, Aliyari Amirabadi R. Evaluation of health, safety, and environment attitude among office workers. Occupat Hyg Health Prom. 2017;1(1):1-9. [Persian]

19. Azadeh A, Mohammad Fam I. The evaluation of importance of safety behaviors in a steel manufacturer by entropy. J Res Health Sci. 2009;9(2):10-8. PMID: 23344166

20. Hatami $F$. The effects of a safety educational intervention on promoting safety behavior at textile workers. Hormozgan Med J. 2013;17(4):333-45. [Persian]

21. Mazaheri MA, Heidarnia A, Ghofranipour F, Shafie A. The effect of theory-based intervention on promote workers' safe behavior in Isfahan Steel company. J Isfahan Med Sch. 2010;27(102):1-11.

22. Zeidi IM, Hajiaghaye AP, Zeidi BM. Investigating the effect of education based on the theory of planned behavior on employee safety behaviors. Knowl Health. 2013;8(3):105-1. [Persian]

23. Mohammadi Zeidi I, Pakpour Hajiagha A, Mohammadi Zeidi $B$. Evaluation of educational programs based on the theory of planned behavior on employees' safety behaviors. J Mazandaran Univ Med Sci. 2013;22(97):166-77. [Persian]

24. Alimohammadi I, Amini M. Assessing safety culture and its influencing factors in a detergent products manufacturing company. Health Saf Work. 2013;3(2):67-78. [Persian]

25. Mesbah F, Choobineh A, Tozihian T, Jafari P, Naghibalhosseini $F$, Shidmosavi $M$, et al. Ergonomic intervention effect in reducing musculoskeletal disorders in staff of Shiraz Medical School. Iran Occupat Health. 2012;9(1):41-51. [Persian]

26. Mohammadfam I, Neazamodini Z. Effect of technical intervention in promoting safety culture assessment. Jundishapur J Health Sci. 2010;2(2):66-74.

27. Whitman LE, Jorgensen M, Gorrepati N. Rater-Reliability of a 5S audit checklist. iniie annual conference. Georgia: Institute of Industrial and Systems Engineers (IISE); 2014. 